\title{
First trimester fetal anatomy scan and identification of major anomalies: A cross sectional study
}

\author{
Fouad $\mathrm{M}^{1}$, Al Darwish $\mathrm{AG}^{1}$, Abdelhamid A ${ }^{1}$, Mohammed SM${ }^{1}$ and Abbas AM${ }^{2 *}$ \\ ${ }^{1}$ Department of Obstetrics \& Gynecology, Faculty of Medicine, Al-Azhar University, Assiut, Egypt \\ ${ }^{2}$ Department of Obstetrics \& Gynecology, Faculty of Medicine, Assiut University, Assiut, Egypt
}

\begin{abstract}
Objective: to validate the use of the first trimester ultrasound scan not just as a screening tool for chromosomal anomalies, but also as a method to identify the major anatomic anomalies.

Methods: a cross-sectional study of 500 pregancies at first trimester of gestation. The cases were selected from Al Azhar University Assuit Hospital and Luxor International hospital outpatient clinic, Obstetrics and Gynecology department. Ultrasound examinations were performed at Al Azhar University Assuit Hospital and Luxor International Hospital (Obstetrics and Gynecology department). Each pregnant woman was scheduled for two ultrasound examinations: First ultrasound was done at the time of booking (11-14 weeks) and a second examination was scheduled at mid trimester between 18-22 weeks done by trans-abdominal ultrasound.

Results: Diabetes mellitus was the most common medical disorder present in about 15\% of women. There were 69 cases (13.8\%) were pregnant in twin gestation. There were 34 cases $(6.8 \%)$ of included women had a history of previous congenital anomalies in previous fetuses. There were 18 cases ( $32.7 \%$ ) who did not take folic acid at all developed congenital anomalies. There were significant differences between both groups regarding the occurrence of anomalies in all medical disorders except asthma ( $p$ < 0.05 ). Diabetes was the most common disorder associated with anomalies in $36.2 \%$ of cases. There was a statistical significant difference between women with abnormal mean CRL and GS diameters measured in first trimester and the development of fetal congenital anomalies either detected in the first or second trimesters $(\mathrm{p}<0.001)$.
\end{abstract}

Conclusions: None of both gestational ages (13-16 weeks and 18-20) is clearly superior to the other. As at 13-16 weeks has the advantage that most lethal malformations will be detected early in pregnancy allowing early termination and at 18-20 weeks is associated with a slightly higher detection rate of major malformations.

\section{Introduction}

During the past decade the diagnostic capabilities and applications of ultrasound have increased dramatically. Since its development ultrasonography has revolutionized modern obstetric medicine and allowed for accurate early screening and visualization in intra-uterine progress. Recent technology advances have allowed early screening and detection of the anomalies that allows earlier intervention and better counseling. In (2013), Salomon et al. stated that routine ultrasound examination is a traditional part of antenatal care if resources are obtainable and access is achievable [1]. It is usually executed in the second trimester, although routine scanning is offered increasingly during the first trimester, especially in high resource settings.

In general, screening for fetal structural and chromosomal abnormalities is a crucial part of antenatal care, the main purpose of a fetal ultrasound scan is to provide precise information that will simplify the delivery of enhanced antenatal care with the best possible outcomes for both the mother and fetus [2]. In (2004), Timor-Tritsch et al. cited that "ultrasound examination, with state-of-the-art equipment and in expert hands, can visualize as many structures at 13-14 weeks as it could at 16 weeks 5-10 years previously and at 20-22 weeks 15-20 years previously" [3]. Towards the end of the first trimester, the scan additionally offers an opportunity to identify gross fetal irregularities and, in health systems that offer first trimester aneuploidy screening, the measuring of the nuchal translucency thickness (NT) is also available
Salomon et al. 2013 and other authors agreed in their study performance of first-trimester fetal ultrasound scan that was conducted in that the first-trimester screening should include NT measurement [1]. Not only this but also most experts advise that NT should be measured between 11 and $13+6$ weeks, corresponding to a CRL measurement of between 45 and $84 \mathrm{~mm}$. This gestational age window is preferred since the NT as a screening test presents optimally and fetal size that allows accurate diagnosis of major fetal abnormalities to be detected as quickly as possible, thus providing women who are carrying an affected fetus with the option of an early termination of pregnancy. In both low-risk and high-risk pregnancies the second trimester "18- 22 weeks" scan is considered the optimal, yet it is also the standard of care for fetal anatomical evaluation.

This has led to $70-90 \%$ detection rate for fetal congenital abnormalities [4]. After about 18 weeks fetal anatomy is evaluated thoroughly through ultrasound. Specifics of standards fetal anatomic evaluations are specified in the American institute of ultrasound in

${ }^{\star}$ Correspondence to: Ahmed M. Abbas, MD, Department of Obstetrics and Gynecology, Assiut University, Women Health Hospital, Assiut Egypt, Tel: +20 10033851833, +20882414616; E-mail: bmr90@hotmail.com

Key words: anatomy scan, first-trimester, congenital anomalies

Received: December 07, 2018; Accepted: December 20, 2018; Published: December 28, 2018 
medicine practice guidelines. It is essential to use methodical routine in the implementation and assessment of anatomic survey to assure complete evaluation of fetal anatomy [5]. Unlike the first trimester ultrasonography that mainly emphases on nuchal translucency measurement in the assessment of chromosomal syndrome risk; yet, the second trimester ultrasound can detect much more precise defects that follow a different pattern for each genetic syndrome. Not only this but also, some fetal anatomy are more easily visualized later in the second trimester [5].

\section{Aim of work}

The aim of the work is to validate the use of the first trimester scan not just as a screening tool for chromosomal anomalies, but also as a method to identify the major anatomic anomalies.

\section{Patients and methods}

\section{Study design}

This is a cross-sectional study of 500 pregancies at first trimester of gestation using a combination of trans-abdominal and trans-vaginal ultrasound.

\section{Setting}

During 12 months study period a total of 500 unselected pregnant women with a mean gestational age of 12 weeks +3 days (11-14 weeks) agreed to participate in the study.

The cases were selected from Al Azhar University Assuit Hospital and Luxor International hospital outpatient clinic, Obstetrics and Gynecology department. Ultrasound examinations were performed at Al Azhar University Assuit Hospital and Luxor International Hospital (Obstetrics and Gynecology department). The machines used in the study were (Accuvix XQ, Medison, Korea) and (Voluson 730 Pro V ,General Electric, USA ). The scans were done by the transabdominal probe $(3.5 \mathrm{MHz})$ for the transabdominal ultrasound and the transvaginal probe $(6.5 \mathrm{MHz})$ for the trans-vaginal ultrasound.

Two-dimensional ultrasound examination was done by the qualified members of Luxor International Hospital. A check list was filled at the completion of each examination.

\section{Participants} criteria:

Pregnant women included in the study have the following selection

\section{Inclusion criteria}

1. Gestational age $(11+0$ weeks to $13+6$ weeks $)$ for the early scan (equivalent to CRL of $45-84 \mathrm{~mm}$ ), and ( $18+0$ weeks to $21+6$ weeks) for the late scan.

\section{Singleton and multiple pregnancies}

3. All pregnant women in Luxor international hospital coming for antenatal care at first trimester were included after written consent.

\section{Exclusion criteria}

1. Gestational age more than 13 weeks +6 days and less than 11 weeks for the early scan, and more than 21 weeks +6 days for the late scan.

2. Poor visualization of the fetus due to technical factors (e.g. obesity, surgical scar) History of noncompliance with prenatal visits with the current or prior pregnancy.

\section{Enrollment}

Each pregnant woman was scheduled for two ultrasound examinations:

1. First ultrasound was done at the time of booking (11-14 weeks) done trans abdominal and followed by trans-vaginal sonography after taking their written consent and these study groups were further divided into two subgroups (11-12+2 weeks) and (12+3-14 weeks) gestational age.

2. A second examination was scheduled at mid trimester between 18-22 weeks done by trans-abdominal ultrasound. Seven cases were found to be missed miscarriages or ongoing spontaneous abortions at the time of the 11-14 weeks scan, so they were considered drop out cases and excluded.

\section{Methods}

The women were subjected to the following:

1. Detailed history taking

2. Clinical examination:

(a) General examination: pulse, temperature, blood pressure, body weight and height, body mass index.

(b) Abdominal examination.

3. Ultrasonography to calculate gestational age, fetal growth, amniotic fluid and to exclude any congenital malformation.

4. All routine investigations: $\mathrm{CBC}, \mathrm{Rh}$, blood grouping, blood sugar, kidney functions tests, liver enzymes.

5. Complete urine analysis and culture \& sensitivity.

6. All pregnant women were subjected in first trimester to ultrasonographic scan using 10 standardized scans as screening method to identify many of the major fetal anatomical anomalies ultrasound machine (Accuvix XQ, Medison ,Korea) and (Voluson 730 Pro V, General Electric, USA ).

7. All pregnant women were subjected again at 18-22 weeks to ultrasonographic scan

\section{Statistical analysis}

SPSS version 22 (IBM Corp., Armonk, NY, USA) was used for statistical analysis. Quantitative data was expressed as mean \pm standard deviation (SD) while qualitative data was expressed as (frequency and percentage). Student t test was used to compare means and Chi square to compare categorical data. $\mathrm{P}<0.05$ was used for statistical significance.

\section{Results}

Table 1 show the demographic and baseline criteria of the study participants. Table 2 shows the percentage of included women with medical disorders. Diabetes mellitus was the most common one present in about $15 \%$ of women. There were 69 cases $(13.8 \%)$ were pregnant in twin gestation. There were 34 cases $(6.8 \%)$ of included women had a history of previous congenital anomalies in previous fetuses.

The most common anomalies diagnosed in the first trimester were presented in Table 3. Table 4 show the relation between folic acid intake in first trimester and the rate of anomalies diagnosed in the second trimester. There were 18 cases $(32.7 \%)$ who did not take folic acid at all developed congenital anomalies. Table 5 shows the relation between 
Table 1. The baseline criteria of the study participants

\begin{tabular}{|c|c|c|}
\hline Variables & No. & $\%$ \\
\hline \multicolumn{3}{|l|}{ Age } \\
\hline Range & \multicolumn{2}{|c|}{$19-43$} \\
\hline Mean \pm SD & \multicolumn{2}{|c|}{$27.35 \pm 5.01$} \\
\hline \multicolumn{3}{|l|}{ Residence } \\
\hline Urban & 208 & 41.6 \\
\hline Rural & 292 & 58.4 \\
\hline \multicolumn{3}{|l|}{ Parity } \\
\hline Multipara & 417 & 83.4 \\
\hline Primipara & 83 & 16.6 \\
\hline \multicolumn{3}{|c|}{ Consanguinity } \\
\hline No & 153 & 30.6 \\
\hline Yes & 347 & 69.4 \\
\hline \multicolumn{3}{|l|}{ BMI } \\
\hline Range & \multicolumn{2}{|c|}{$20.9-44.5$} \\
\hline Mean \pm SD & \multicolumn{2}{|c|}{$32.25 \pm 5.22$} \\
\hline \multicolumn{3}{|l|}{ Smoking } \\
\hline No & 333 & 66.6 \\
\hline Yes & 167 & 33.4 \\
\hline
\end{tabular}

Table 2. The medical history of the study participants

\begin{tabular}{|l|c|c|}
\hline Variables & No. & \% \\
\hline Diabetes & & 84.6 \\
\hline No & 77 & 15.4 \\
\hline Yes & & \\
\hline Hypertension & 443 & 88.6 \\
\hline No & 57 & 11.4 \\
\hline Yes & & 97.2 \\
\hline Cardiac & 486 & 2.8 \\
\hline No & 14 & 98.8 \\
\hline Yes & & 1.2 \\
\hline Systemic lupus & 694 & 93.6 \\
\hline No & & 6.4 \\
\hline Yes & 468 & 86.2 \\
\hline Asthma & 32 & 13.8 \\
\hline No & & \\
\hline Yes & 431 & 93.2 \\
\hline No. of baby & 69 & \\
\hline Single & & \\
\hline Twin pregnancy & 466 & \\
\hline History of congenital anomaly & & \\
\hline No & & \\
\hline Yes & & \\
\hline
\end{tabular}

medical disorders the occurrence of congenital anomalies. There were significant differences between both groups regarding the occurrence of anomalies in all medical disorders except asthma $(\mathrm{p}<0.05)$. Diabetes was the most common disorder associated with anomalies in $36.2 \%$ of cases.

Table 6 shows a statistically significant difference between women with abnormal mean CRL and GS diameters measured in first trimester and the development of fetal congenital anomalies either detected in the first or second trimesters $(\mathrm{p}<0.001)$.

\section{Discussion}

As a result of the advent of trans-vaginal sonography (TVS), fetal anomaly screening has been suggested for more than 25 years [6]. Sonography is commonly used for diagnosis of fetal anomalies around mid-gestation. However, with current technology some malformations may be recognized in the late first to early second trimester [7].
It is important to establish whether fetal anatomy can be consistently and precisely visualized at early gestational age. Should structural abnormalities be detected in the first trimester, prenatal diagnosis could be offered at an earlier stage, allowing the option of an early versus a late termination of pregnancy with a resulting decrease in surgical complications and psychiatric morbidity [8]. Also, certain ultrasonographic findings in the first trimester, e.g. increased nuchal translucency, cystic hygroma and omphalocele, have been described in association with chromosomal abnormalities [9].

In the last decade, the first trimester scan has played a crucial role not just for evaluating the fetal viability and determining the gestational age, but also as a screening tool for the identification of chromosomal

Table 3. The types of congenital anomalies diagnosed in $1^{\text {st }}$ trimester in relation to previous history of congenital anomalies in the study participants

\begin{tabular}{|c|c|c|c|c|c|}
\hline \multirow{3}{*}{$\begin{array}{l}\text { Anomaly found ( } 1^{\text {st }} \\
\text { trimester) }\end{array}$} & \multicolumn{4}{|c|}{ History of anomaly } & \multirow{3}{*}{ P-value } \\
\hline & \multicolumn{2}{|c|}{ No } & \multicolumn{2}{|c|}{ Yes } & \\
\hline & No. & $\%$ & No. & $\%$ & \\
\hline No & 437 & 93.8 & 16 & 3.4 & \multirow{8}{*}{$<0.001^{*}$} \\
\hline Acrania & 2 & 0.4 & 4 & 11.8 & \\
\hline Anencephaly & 4 & 0.9 & 0 & 0.0 & \\
\hline Cystic Hygroma & 0 & 0.0 & 2 & 5.9 & \\
\hline Abnormal N.T & 10 & 2.1 & 0 & 0.0 & \\
\hline Hydrocepalus & 4 & 0.9 & 8 & 23.5 & \\
\hline Microceplahy & 4 & 0.9 & 0 & 0.0 & \\
\hline Spina bifida & 2 & 0.4 & 0 & 0.0 & \\
\hline
\end{tabular}

Table 4. Relation of folic acid intake to the congenital anomalies present in the second trimester

\begin{tabular}{|c|c|c|c|c|c|c|}
\hline \multirow{3}{*}{$\begin{array}{l}\text { Anomaly found ( } 2^{\text {nd }} \\
\text { trimester) }\end{array}$} & \multicolumn{6}{|c|}{ Folic acid taken } \\
\hline & \multicolumn{2}{|c|}{$\operatorname{Preconception}(n=34)$} & \multicolumn{2}{|c|}{ Conception $(n=445)$} & \multicolumn{2}{|c|}{ No(n=55) } \\
\hline & No. & $\%$ & No. & $\%$ & No. & $\%$ \\
\hline No $(n=453)$ & 28 & 82.4 & 416 & 93.5 & 37 & 67.3 \\
\hline Yes $(n=47)$ & 6 & 17.6 & 29 & 6.5 & 18 & 32.7 \\
\hline P-value & \multicolumn{2}{|c|}{$<0.001^{*}$} & \multicolumn{2}{|c|}{$<0.001 *$} & \multicolumn{2}{|c|}{$<0.001 *$} \\
\hline
\end{tabular}

* Statistical significant difference

Table 5. Relation of medical disorders to the congenital anomalies present in the second trimester

\begin{tabular}{|c|c|c|c|c|c|}
\hline & \multicolumn{4}{|c|}{ Anomaly found ( $2^{\text {nd }}$ trimester) } & \multirow{3}{*}{ P. value } \\
\hline & \multicolumn{2}{|c|}{ No $(n=453)$} & \multicolumn{2}{|c|}{ Yes $(n=47)$} & \\
\hline & No. & $\%$ & No. & $\%$ & \\
\hline DM $(n=77)$ & 60 & 13.2 & 17 & 36.2 & $<0.001^{*}$ \\
\hline $\begin{array}{l}\text { Hypertension } \\
(\mathrm{n}=57)\end{array}$ & 48 & 10.6 & 9 & 19.1 & $0.040^{*}$ \\
\hline Cardiac $(n=14)$ & 4 & 0.9 & 10 & 21.3 & $<0.001^{*}$ \\
\hline $\operatorname{SIE}(n=6)$ & 2 & 0.4 & 4 & 8.5 & $<0.001^{*}$ \\
\hline Asthma (n=32) & 28 & 6.2 & 4 & 8.5 & 0.791 \\
\hline
\end{tabular}

* Statistical significant difference

Table 6. Relation of mean CRL and GS measures in the first trimester to the congenital anomalies present in the first and second trimesters

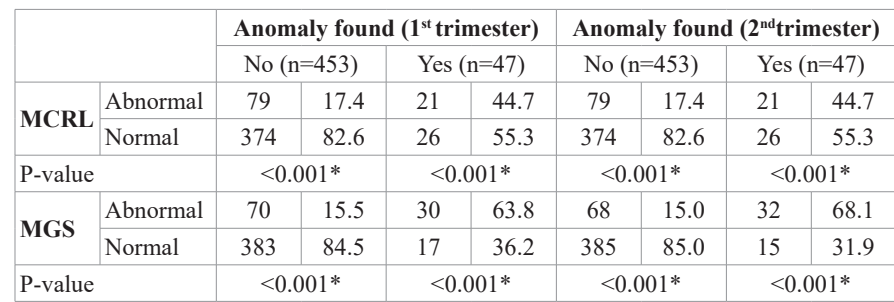

* Statistical significant difference 
anomalies measuring the fetal nuchal translucency thickness (NT) [10]. Furthermore, several studies showed the capacity of the first trimester scan to identify more than the $80 \%$ of the major fetal malformations not related to chromosomopathies, with sensitivity between 12.5 and $83.7 \%$ [11].

Our study included 500 pregnant women in their late first or early second trimester. The mean age of the pregnant women in our study ranged from 19-43 years, with a mean of $27.4 \pm 5$ years. The study done by Colosi et al. 2015 included 5924 cases over a period of more than 5 years, with a mean age of 32.2 years (somewhat older than our cases) and a range from 16-47 years (wider range than our cases) [12]. This was reflected to the high percentage (over 35\%) of their cases aged more than 35 years. Also, the study done by Liu et al. 2017 on 9466 cases had a mean maternal age of 31.5 years, with a range from 16-51 years [13].

Regarding BMI, cases ranged from average BMI to morbid obesity (with a BMI range 21-44.5; mean $32.3 \pm 5.2$ ). Our cases were more obese than those of Colosi et al. 2015 study, where the mean BMI was only 27.6 [12].

Anatomical anomalies were detected in 47 cases (9.4\%), of them 18 cases had past history of anomalies in at least one of the previous pregnancies, and 29 had no past history. This means that those with positive past history had more than $50 \%$ risk to develop anomalies in the current pregnancy compared to a risk of only around $6 \%$ among those without past history. The difference was, of course, highly significant.

Regarding the anomalies detected, hydrocephalus was the most common anomaly; found in 14 cases. This was followed by abnormal NT (in 10 cases); then acrenia (6 cases), anencephaly (4 cases) and microcephaly (6 cases), brachydactyly, cystic hygroma, and spina bifida ( 2 cases each) and lastly ovarian cyst in one case. In the study done by Colosi et al. [12], neurological anomalies were the most common (representing $45.4 \%$ of all anomalies detected), followed by structural trunk anomalies, then cardiac and skeletal anomalies.

We found that there was a significant and reverse relationship between folic acid intake and the risk to develop anatomical anomalies. Also, we found that the incidence of anomalies was significantly higher among mothers with chronic diseases (DM, HTN, cardiac diseases and SIE). The only exception was asthma, which was not associated with significant rise in the development of anatomical anomalies.

In our study, residence and BMI were not associated with increased risk of anatomical anomalies among our study population. On the other hand, smoking, drug intake, advanced age of the mother; all were associated with significant rise in the risk of anatomical anomalies.

\section{Conclusions}

None of both gestational ages (13-16 weeks and 18-20) is clearly superior to the other. As at 13-16 weeks has the advantage that most lethal malformations will be detected early in pregnancy allowing early termination and at $18-20$ weeks is associated with a slightly higher detection rate of major malformations. Recommendations for future studies, more patients and multi centric studies are needed to allow detection of congenital anomalies.

\section{Conflict of interest}

The authors declare that they have no conflict of interest.

\section{References}

1. Salomon LJ, Bernard M, Amarsy R, Bernard JP, Ville Y (2013) The impact of crownrump length measurement error on combined Down syndrome screening: a simulation study. Ultrasound Obstet Gynecol. 33:506-511.

2. Salomon LJ, Alfirevic Z, Bilardo CM, Chalouhi GE, Ghi T, et al. (2013) ISUOG practice guidelines: performance of first-trimester fetal ultrasound scan. Ultrasound Obstet Gynecol 41: 102-113. [Crossref]

3. Timor-Tritsch IE, Bashiri A, Monteagudo A, Arsian AA (2004) Qualified and trained sonographers in the US can perform early fetal anatomy scans between 11 and 14 weeks. Am J Obstet Gynecol 191:1247-1252.

4. Souter VL, Nyberg DA (2001) Sonographic screening for fetal aneuploidy: first trimester. J Ultrasound Med 20: 775-790. [Crossref]

5. Conner SN, Longman RE, Cahill AG (2014) The role of ultrasound in the diagnosis of fetal genetic syndromes. Best Pract Res Clin Obstet Gynaecol 28: 417-428. [Crossref]

6. Timor-Tritsch IE, Monteagudo A, Peisner DB (1992) High-frequency transvaginal sonographic examination for the potential malformation assessment of the 9-week to 14-week fetus. J Clin Ultrasound 20: 231-238. [Crossref]

7. Monteagudo A, Timor-Tritsch IE (2003) First trimester anatomy scan: pushing the limits. What can we see now? Curr Opin Obstet Gynecol 15: 131-141. [Crossref]

8. Leone T, Coast E, Parmar D, Vwalika B (2016) The individual level cost of pregnancy termination in Zambia: a comparison of safe and unsafe abortion. Health Policy Plan 31: 825-833.

9. Snijders RJ, Brizot ML, Faria M, Nicolaides KH (1995) Fetal exomphalos at 11 to 14 weeks of gestation. J Ultrasound Med 14: 569-574. [Crossref]

10. Nicolaides KH, Wegrzyn P (2005) First trimester diagnosis of chromosomal defects. Ginekol Pol 76: 1-8.

11. Souka AP, Pilalis A, Kavalakis I, Antsaklis P, Papantoniou N, et al. (2006) Screening for major structural abnormalities at the 11- to 14-week ultrasound scan. Am J Obstet Gynecol 194: 393-396. [Crossref]

12. Colosi E, Musone R, Filardi G, Fabbo A (2015) First trimester fetal anatomy study and identification of major anomalies using 10 standardized scans. J Prenat Med 9: 24-28.

13. Liu S, Wu Q, Chen Z (2017) Fetal anomalies detection in China by screening with ultrasound. Biomed Res 28: 4891-4896.

Copyright: (C2018 Fouad M. This is an open-access article distributed under the terms of the Creative Commons Attribution License, which permits unrestricted use, distribution, and reproduction in any medium, provided the original author and source are credited. 